\title{
Economic Shocks of Covid-19: Can Big Data Analytics Help Connect the Dots
}

\author{
Hakimah Yaacob, Qaisar Ali*, Nur Anissa Sarbini, Abdul Nasir Rani, Zaki Zaini, Nurul Nabilah Ali \\ and Norliza Mahalle
}

\author{
Faculty of Islamic Economics and Finance (FEKIM), Universiti Islam Sultan Sharif Ali, BE1310, Brunei Darussalam \\ ${ }^{*}$ Corresponding Author: Qaisar Ali. Email: aliqaisar21@gmail.com \\ Received: 09 November 2020; Accepted: 18 December 2020
}

\begin{abstract}
Since the beginning of the Covid-19 pandemic, big data analytics (BDA) remains a signatory medium in the battle against it. Governments and policymakers alike are yet to leverage on this scalable technology in an attempt to curb the economic effects of Covid-19. The primary objective of this study is to leverage on BDA to identify economic shocks, and propose a strategic solution for economic recovery in ASEAN member states (AMS). The findings of this study suggest that BDA techniques, frameworks, and architectures are effective tools in predicting and tracking economic shocks, as well as in designing and implementing an effective economic recovery plan. This study proposes a guideline to governments and policymakers scrambling for resources and considering different options to start an economic recovery process. Our findings draw a roadmap for complex AMS economies struggling to explore options for economic recovery in the response of Covid-19. This study has extended and confirmed the knowledge and perception about harnessing BDA as a tool as well as proposed a scientific approach to design economic policies. The findings outlined in this study contribute to the pipeline of BDA's theoretical frameworks which is expected to strengthen its novelty in data science.
\end{abstract}

Keywords: Covid-19; economic shocks; Big data analytics; economic recovery; ASEAN; policymakers

\section{Introduction}

The respiratory infection caused by the SARS-CoV-2 virus is known as the Coronavirus Disease 2019 (Covid-19), and was first reported in China's Hubei (Wuhan) district on 31 December 2019 [1]. Covid-19 holds the world in limbos as nations battle to curtail the spread of the infection. As of 14 August 2020, Covid-19 had claimed 656,093 lives and infected more than 20.66 million people in 203 countries [2]. Following its exponential growth, the World Health Organization (WHO) declared it as a global pandemic on 11 March 2020 [1]. Initially, the outbreak was restricted to China however, the disease readily spread to neighbouring regions including South Korea, Japan, Iran, and eventually the Southeast Asian Nations (ASEAN), due to enhanced human inter-connectivity, trade and tourism and the propinquity involved in these activities [3].

This work is licensed under a Creative Commons Attribution 4.0 International License, which permits unrestricted use, distribution, and reproduction in any medium, provided the original work is properly cited. 
As of 14 August 2020, the ASEAN member states (AMS) had more than 350,035 confirmed cases and 86, 33 Covid-19 related deaths [2]. The infection rate in the AMS was comparatively low at the start of the pandemic, especially in the Philippines, Indonesia, and Singapore. However, the lack of medical interventions, unprecedented uncertainties, and ineffective mechanisms to contain the outbreak in the AMS indicated the vulnerability of the population towards the disease. This created fear of a possible rise in the number of infected individuals that may subsequently increase mortality rates as well as the effects of morbidity.

The World Bank [4] warned global communities about the serious consequences and morbidity effects of the pandemic. A few general projections are; bottleneck global economic activities, disruption of supply chains and financial markets, negative output of growth, rise in unemployment, business closures and households scrambling to subsist. It is predicted that despite the ability of some countries to successfully contain the spread of the infection, the economic impacts of the pandemic are irreversible [5]. Recent studies and reports on the Covid-19's economic impacts, described it as a black swan event and the worst disaster to hit mankind in over a century [6-9].

Rewinding a few months, global economies, businesses, and investments were optimistic about the output of growth while entering into 2020, despite lingering fears of the US-China trade war [10]. This optimism was overturned by the Covid-19 outbreak, as several global institutions such as International Monetary Fund (IMF). The World Bank, and The Economist warned on the contraction in the global gross domestic product (GDP) to as low as $5.2 \%$. The popular stock market indices such as Dow Jones Industrial Average (DJI), S\&P 500, Nasdaq Composite Index, FTSE, and Nikkei substantially contracted at the start of the outbreak [11].

The economic shocks of Covid-19 are much more diverse in the AMS, despite the comparatively low spread rate. AMS economies are more vulnerable to economic shocks due to the nature of the economies, structural characteristics of the region, and enhanced dependence on China and other countries for trade and investment [3]. About $17.1 \%$ of the total trade and $6.5 \%$ of foreign direct investments of the AMS rely on supply chain integration [12]. Covid-19 is projected to contract international trades by 13 to $32 \%$, therefore economists expect that contraction in international trades will be a grave threat for the AMS economies [13]. AMS are particularly selected for the purpose of this study due to facts associated with the region and the concomitant commitment to strengthen cooperation, health, and security since 1980 [14]. The ASEAN community is established on the mutual pillars of the Political-Security Community, Economic Community, and Socio-Cultural Community (ASCC). These communities used to be cooperated during epidemics in the past such as SARS, H1N1, and MERS-CoV. The ASCC vision discloses AMS commitment to warrant healthy, caring, and sustainable ASEAN community, which was a result of ASEAN Post-2015 Healthier Development Agenda in 2018. However, the nature of the current crises entails a dire need to adopt a discreate holistic approach to ensure the health, security, and economic stability of the AMS.

Nevertheless, the dreadful Covid-19 disease continues to cause havoc with humanity, socio-communal systems, and economies worldwide. Data science powered by machine learning, statistical learning, time series modelling, data visualisation, and their experts holds a key to mitigate the global effects of Covid19, especially, to revive the economic situation in developing countries. Scientists from around the world have used data science to propose simulation models to predict the behaviour of Covid-19 [15], risk assessment and patient prioritisation [16], screening and diagnosis [17], contact tracing [18], understanding social interventions [19] and pharmaceutical research [20].

As the enormity of the Covid-19 economic threats are clear, governments appear to heavily rely on data science such as big data analytics (BDA), artificial intelligence, and the internet of things (IoT), to curb these effects. Big data (BD) has the potential to develop a better and confident decision making that may help in achieving operational efficiency, cost reduction and lower risk [21]. BDA specifically, can help governments 
in scaling efforts to help organisations in business continuity, overcome financial disruptions, increase growth output, recover supply chains, and develop a resilient economic system. ASEAN regions have established an ASEAN Emergency Operations Centre (EOC) through the ASEAN BioDiaspora Virtual Centre (ABVC) in the response of Covid-19 for the visualisation of BDA and facilitation of public health emergency. However, the identification of economic shocks in the face of Covid-19 and leveraging on BDA to propose a strategic solution for economic recovery remains highly inexplicit. Therefore, this study is expected to contribute to the acquisition, harmonisation, automation, and creation of a geospatial insight of BDA to help AMS governments in detecting the shock vulnerable patches in the economy and propose a robust solution to curb these shocks.

The morbidity effects of the Covid-19 pandemic are diverse, thus governments, health professionals, and policymakers are scrambling resources to minimise the effects, by developing a range of response strategies. Even though BDA is extensively used to diagnose patients, conduct contact tracing and remote working, governments and policymakers have yet to truly explore the full potential of BDA. One of the challenges for developing economies, such as the AMS, is to find an economic solution to lower the shocks of the pandemic. Governments consider advance analytics, such as BDA and artificial intelligence (AI) can contribute approximately US\$9.5 to15.4 trillion annually to the economy [22]. Therefore, developing strategies and techniques to leverage on BDA is key to combat economic challenges due to the pandemic. Particularly, we are interested in analysing how to harness BDA in the AMS to combat the economic challenges and propose the implications for governments and policymakers, while authenticating BDA as a principal solution for economic recovery.

This study has three discrete contributions; firstly, it contributes to the literature on economic policies and implications, by suggesting methods to curb economic shocks related to Covid-19. Secondly, it provides the required tools and methods for policymakers, while considering the initiation of an economic recovery process in AMS. Lastly, our study contributes to the pipeline of BDA knowledge and its versatile potential to initiate an economic recovery process, whereby the data may act as a tool while implementing economic recovery policies.

The rest of the paper is organised as follows; section two briefly overviews the economic challenges in AMS. Section three is analyses of the methods and areas of the economy which are vulnerable to shock, and to which BDA can contribute. Section four outlines the policy recommendations for governments and policymakers and section 5 concludes this paper.

\section{Literature Related to Covid-19 Economic Shocks in AMS}

Covid-19 has constrained the economy causing irreversible economic shocks to the global economies. These shocks have escalated uncertainties about economic integration across all AMS. Some of the economic fallouts of Covid-19 in AMS are briefly outlined below.

\subsection{Downturn of GDP Growth}

IMF's [8] revised economic outlook released in June 2020 indicates that Asia and the Pacific will experience zero growth in 2020, being the worst growth scenario for AMS in over 60 years. These projections are based on the paradigms of lack of immunity against Covid-19 and the stringent domestic containment measures by the governments. The imposed safety measures such as cancellation of large scale-events, suspension of flights, the prohibition of business operations at full capacity, and restriction of movements have halted the exclusive initiation of economic activities in AMS. The effects of the pandemic on GDP growth can be estimated by comparing the GDP growth in AMS before the start of the Covid-19 outbreak and GDP growth amid the pandemic, which is presented below in Tab. 1. 
Table 1: A comparison of GDP growth before and during Covid-19

\begin{tabular}{llllll}
\hline Country & Before Covid-19 outbreak & \multicolumn{2}{l}{ During Covid-19 outbreak } & Source \\
\hline BRN & $1.5 \%$ & Sep 2019 & $2.0 \%$ & 3 Apr 2020 & ADB \\
KHM & $6.8 \%$ & Sep 2019 & $2.3 \%$ & 3 Apr 2020 & ADB \\
IDN & $5.3 \%$ & Official target, Aug & $-0.4 \%$ to $2.3 \%$ & 1 Apr 2020 & MOF \\
& & 2019 & & & \\
LAO & $6.2 \%$ & Sep 2019 & $3.5 \%$ & 3 Apr 2020 & ADB \\
MYS & $4.8 \%$ & Official target & $3.2 \%$ to $4.2 \%,-2.0 \%$ to & Feb 2020- April 3, & MOF, \\
& & & $0.5 \%$ & 2020 & BNM \\
MMR & $6.8 \%$ & Sep 2019 & $4.2 \%$ & 3 Apr 2020 & ADB \\
PHL & $6.5 \%$ to & Official target & $-0.6 \%$ to $4.3 \%$ & 19 Mar 2020 & NEDA \\
& $7.5 \%$ & & & & \\
SGP & $0.5 \%$ to & Nov 2019 & $-4 \%$ to $-1 \%$ & 26 Mar 2020 & MOTI \\
& $2.5 \%$ & & & & B Apr 2020 \\
THA & $2.8 \%$ & Dec 2019 & $-5.3 \%$ & 9 March 2020 & MOPI \\
VNM & $6.8 \%$ & - & $6.09-6.27 \%$ & &
\end{tabular}

Source: ASEAN policy brief, 2020

The table shows that GDP growth projections in AMS were positive and optimistic before the outbreak, however, these projections started to deteriorate as Covid-19 unfolded in the region. Even though the infection rate in the region is relatively low, yet the GDP growth projections are negative. This is due to plunging oil prices, pressure on asset prices such as equity and fixed income markets, trade and investment interdependence on hard-hit Covid-19 countries, informal economic nature of AMS, lack of social protection system and high revenue-generating businesses being largely affected by Covid-19.

\subsection{Disruption of Trade, Tourism and Production}

Covid-19 has an immediate effect on socio-economic lives, and it has disrupted the trade, tourism, and production industries in AMS [23]. The restriction on movements has disrupted supply chains, declined demand for goods, and limited the flow of trade and investments. The epicentres of Covid-19 such as China, US and EU are the largest strategic trade partners and investors in AMS. Ref. [13] report predicted the decline in global trade by 13 to $32 \%$ in 2020 , which will reduce the flow of trade and investment to AMS. Additionally, there is a rising fear of a decline in trade in 2020 to the countries that heavily rely on complex value chains. Tab. 2 below presents an overview of the cumulative trade volume of AMS with its global partners.

Travel and tourism are significant economic contributors in AMS, amounting to $12.6 \%$ of the total revenue. The outbreak lead AMS to suspend flights to and from China which had a negative influence on the economies, as Chinese tourists account for nearly $20 \%$ of inbound tourists in eight AMS. Cambodia, Philippines, and Thailand are rendered as the most vulnerable regions among other AMS, since the travel and tourism sectors in these countries largely contribute to the GDP, employment, and export revenue [10]. Similarly, the production capacities of many businesses in the entire region have significantly declined due to the temporary closure of businesses, schools, and cancellation of all major events, to necessitate social distancing. 
Table 2: Global trade partners' share in ASEAN

\begin{tabular}{|c|c|c|c|c|c|c|}
\hline \multirow[t]{2}{*}{ Trade partners } & \multicolumn{3}{|c|}{ Trade (US\$ billion) } & \multicolumn{3}{|c|}{ Share to ASEAN total $(\%)$} \\
\hline & Total trade & Export & Import & Total trade & Export & Import \\
\hline ASEAN Total & $2,825.3$ & $1,436.4$ & $1,388.8$ & 100.00 & 100.00 & 100.00 \\
\hline Intra-ASEAN & 650.7 & 346.5 & 304.3 & 23.03 & 24.12 & 21.91 \\
\hline China & 483.8 & 199.0 & 284.8 & 17.12 & 13.85 & 20.51 \\
\hline $\mathrm{EU}$ & 160.9 & 127.3 & 9.17 & 10.20 & 11.20 & 288.2 \\
\hline US & 263.0 & 160.3 & 102.7 & 9.31 & 11.16 & 7.40 \\
\hline Japan & 231.7 & 114.8 & 116.9 & 8.20 & 7.99 & 8.42 \\
\hline Korea & 161.5 & 60.5 & 101.0 & 5.72 & 4.21 & 7.27 \\
\hline Hong Kong, China & 118.3 & 100.2 & 18.1 & 4.19 & 6.98 & 1.30 \\
\hline Chinese Taipei & 117.4 & 39.7 & 77.6 & 4.15 & 2.77 & 5.59 \\
\hline India & 81.1 & 50.7 & 30.3 & 2.87 & 3.53 & 2.18 \\
\hline Australia & 66.2 & 39.2 & 27.0 & 2.34 & 2.73 & 1.94 \\
\hline
\end{tabular}

Source: ASEAN policy brief, 2020

\subsection{MSMEs Businesses Continuity}

AMS' governments have announced fiscal packages to support micro, small and medium enterprises (MSMEs) with a median value of about 3.5\% of the GDP [24]. However, the pandemic has exerted a steeply increasing pressure on the businesses, some of which already loaded with debts and facing growth challenges. The duration of the current pandemic has raised doubts among AMS businesses about their survival and existence, for instance, in the UK, five out of six businesses declared their doubts and inability of business continuity [25]. The uncertainties of the current crises will lead AMS businesses scrambling for bankruptcy, resulting in a chain reaction of new bankruptcies due to the lack of demand, supply of goods, and services. AMS economies have a large number of MSMEs which require fiscal financial support, clarity about policy direction, and a supportive business environment to cushion their survival during the current economic downturn. Therefore, MSMEs are more vulnerable to economic shocks as these countries' economic conditions lowers their capacity to borrow from domestic and international markets, to provide support to the most marginalised sectors of the community [24].

\subsection{Financial Market Disruption}

The deteriorating global growth and persistently low inflation have forced major central banks worldwide to adopt a more accommodative policy stance for the near term [26]. For example, the disruption of financial markets caused by the Covid-19 forced the U.S. Federal Reserve to place a tightening cycle on hold, similarly, the European Central Bank delayed the end of its negative interest rate due to a drop in long-term yields. These are the lowest levels in the U.S. since 2017, Similarly in Germany, government bonds yielded below zero for the first time since 2016 (Figs. 1 and 2).

The escalating trade tension between the U.S. and China had already moderated foreign investments in AMS long before the start of the pandemic. The global trade tension declined the stocks of equity portfolio in AMS by $25.1 \%$ as the major investors, U.S. and E.U withdrew. The countries highly affected by the pandemic are the largest holders of equity (U.S. 38.4\%; E.U. 27.1\%), cumulative debt investment stock (U.S. 22.2\%; E.U. 30.6\%) and foreign direct investments (U.S. 14.1\%; E.U. 18.7\%) in AMS. The tight global financing conditions across the world and in AMS will prevail provided the pandemic continues. 
The stock markets in AMS significantly plummeted from the start of the outbreak, whereas, stock markets in Indonesia, Philippines, Thailand, and Vietnam were exceptionally wiped out. The stock markets in Vietnam dropped by $29.3 \%$ however, in Malaysia the downward trend was relatively controlled as it declined by $11.8 \%$.

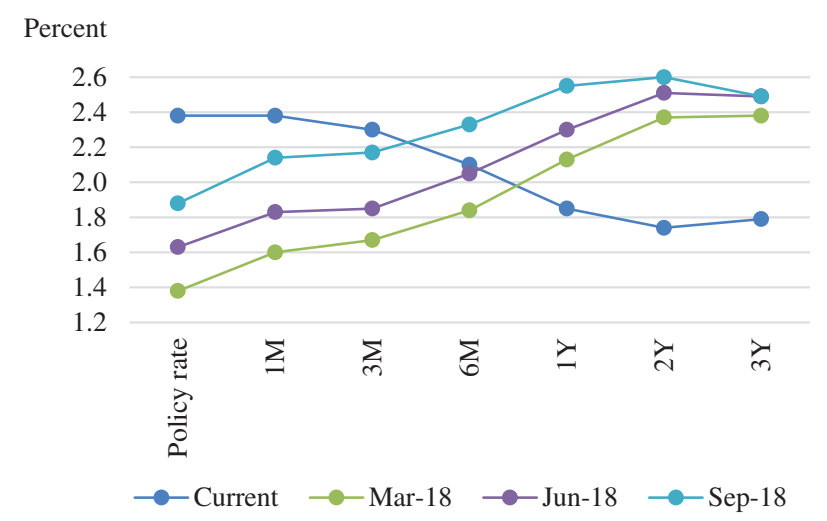

Figure 1: U.S. federal funds rate expectations (Source: Bloomberg, World Bank)

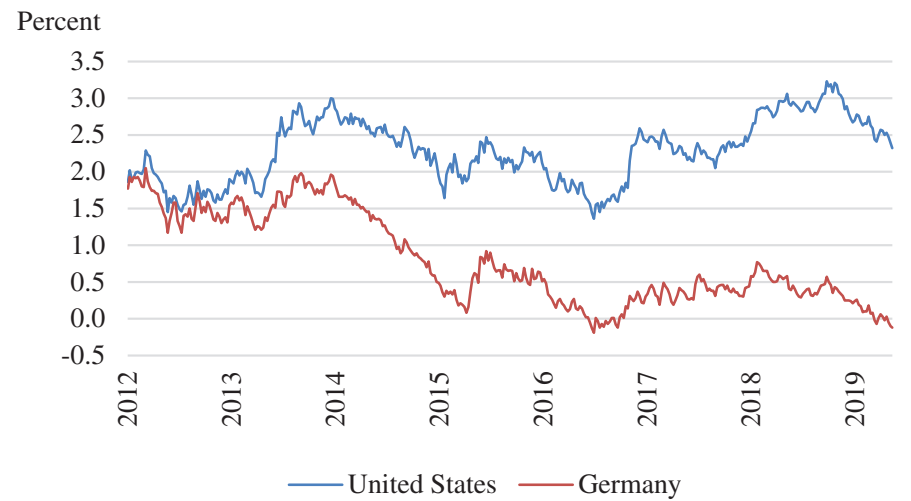

Figure 2: U.S. and German 10-year government bond yields (Source: Bloomberg, World Bank) Note: The figure shows weekly data. The last observation was on May 23, 2019.

The exchange rates in Thailand, Indonesia (19.8\%), and Singapore experienced the largest depreciation among other AMS. The debt to GDP proportion of most AMS is more than $30 \%$, which indicates the overreliance on reserves of foreign exchange. The continuous depreciation in the exchange rate will escalate debt payment and increase the risks of debt sustainability. This will increase the borrowing cost and force AMS to turn to multilateral institutions to fill the financing gaps. For instance, Cambodia, Indonesia, Laos PDR, Myanmar, and the Philippines have recently used The World Bank's Covid-19 Fast-Track and other financial support facilities [24].

\section{Methodology}

This is a qualitative study based on the secondary sources of data collected after reviewing and systematic evaluation of various documents [27]. The evaluation of documents helps in collecting background information and tracking changes and new development in the case under investigation [28]. Particularly, documents related to Covid-19 and its economic impacts in AMS and existing literature on capabilities of BDA to provide solutions to combat the pandemic are reviewed. Firstly, this study 
considered reports from the World Bank, IMF and OECD to outline the economic impacts of Covid-19 in AMS to develop the background information for the case under investigation. Secondly, the findings of ongoing research on BDA to predict, track and combat the outbreak of Covid-19 are used to develop a framework in the economic settings. Lastly, policy documents of the World Health Organisation (WHO), United Nations Economic and Social Commission for Asia and the Pacific (UNESCAP) and ASEAN were considered to propose BDA as a pragmatic solution to minimise the economic shocks in AMS.

\section{Findings and Discussion}

\subsection{BDA Amid Covid-19}

Over the past three centuries, the world has suffered from 10 major pandemics of stronger and lesser magnitude, and Potter [29] had warned to not disregard the possibility of another medical disaster. The world was hit by three major pandemics during the $20^{\text {th }}$ century; the Spanish influenza in 1918 , the Asian influenza in 1957, and the Hong Kong influenza in 1968 killing more than 30 to 60 million people [30]. However, nature of the current health crises is different due to the lack of immediate medical intervention and it has occurred at a time when globalisation is a major concern for the global economies. Covid-19 is rendered as the worst crises among all pandemics, it is characterised as the second most devastating event in over a century due to the speed and magnitude of its spread [9].

Catastrophic events such as pandemics and terrorist attacks are epitomised as the black swan events as it results in shock, fear, and panic, and often generates a huge amount of data known as big data. It is an innovative technology that digitally stores a large amount of data and can help in revealing patients' patterns, associations, and differences [31]. The creation of technologies and architectures to economically extract value and gain a meaningful insight to minimise the risk of the spread of the Covid19 infection has also been described as BDA [32,33].

Additionally, the current pandemic, compared to the past pandemics has occurred in a digitalised and substantially connected world [34]. The advance computational models powered by machine learning have a huge potential to trace and predict the spread of a disease in the future [35]. Hence, it is imperative to leverage on BDA to safeguard public health and wellbeing. BDA coupled with digital technologies such as Internet of Things (IoT) with next-generation telecommunication networks, AI using deep learning, and blockchain technologies, were proposed and leveraged on to tackle the ongoing crises [36]. Thus, BDA was deployed to contain the Covid-19 infection among 627,386 people in Taiwan who were in contact with the Diamond Princess Cruise ship passengers [37]. Other uses of data science include drones delivering food and medicine to the patients and disinfecting streets and public spaces [38]. Two-dimensional (2D) and three-dimensional (3D) chest CT scan analysis are used to quantify infection rate in the infected patients' lungs [39] and the analyses of Weibo data are used to characterise the propagation of Covid-19 related information on social media [19].

\subsection{Leveraging on BDA to Curb Economic Shocks in AMS}

Covid-19 has fully exposed the fragility of AMS economies essentially relying global valued chains for cross-border trade and transport. The region is substantially exposed to economic shocks due to over-leaning to supply chains, where as much as $40 \%$ of its exports rely on value chains [24]. Recent studies have suggested that leveraging on digital technologies such as BDA, is a way forward for countries looking to mitigate the effects of the Covid-19 pandemic. BDA can provide a platform for public agencies to access data for the detection, diagnosis, monitoring, preparation, and education of the policymakers [34,40-41]. The economic shocks of Covid-19 can be tackled through a similar approach; using BDA to detect actual economic impacts, specifically on sectors most affected in the economy, using BDA to diagnose the associated cause of economic shocks, preparing economies for the economic recovery process, 
monitoring the progress of economic recovery and lastly, educating business owners and communities to enhance their resilience in the possible case of future pandemics.

UNESCAP [24] has proposed to leverage on digital technology such as BDA, to strengthen digital supply chains, reduce digital trade barriers, facilitate digital trade and develop digital trade frameworks and trust policies, as a pragmatic solution to revive economies and livelihoods in AMS. Despite pessimistic economic growth forecasts in the region, IMF and Asian Development Bank (ADB) have projected a strong rebound in AMS by $+7.8 \%$ and $+4.7 \%$ in 2021 , respectively [42]. This 'upper case' scenario refers to the discovery of Covid-19 vaccines or AMS economies capping the economic shocks by integrating digital trade through BDA. Additionally, despite strong economic growth, the region is characterised by high inequalities, lower social protection, and large informal sector that push AMS away from the track to achieve sustainable development goals by 2030, even before the emergence of Covid-19 [43].

Simultaneously, most AMS have developed exceptional capabilities to respond to public health emergencies, by readily detecting and reporting epidemics as compared to many developed countries. This reflects the regional commitment to protect and improve public health and lives. Even though AMS has established ASEAN Biodiaspora Virtual Center (ABVC) in response of Covid-19. Yet the mechanism and the effectiveness of visualising BDA, particularly in the context of mitigating economic shocks are largely unexplored. The discussion below elucidates how BDA can be embedded and navigated in the economic systems of AMS to absorb existing shocks and enhance economic resilience.

We propose to mitigate the economic effects of Covid-19 by leveraging on BDA via four main application domains. They are predicting the outbreak during economic shocks, tracking economic shocks proposing solutions and providing policy implications to start the recovery process. Fig. 3 elucidates the suggested BDA model to mitigate economic shocks of Covid-19.

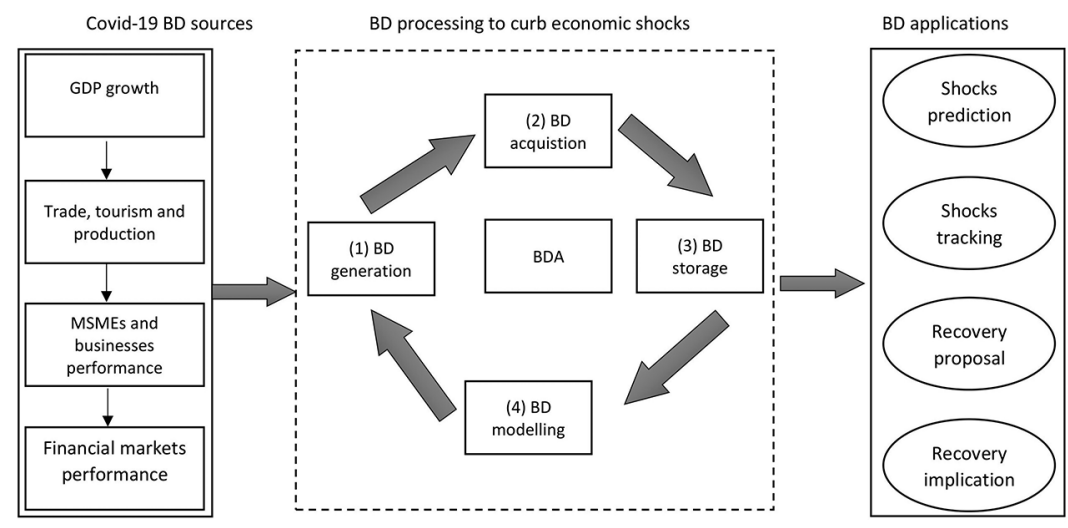

Figure 3: BDA navigation model to mitigate economic shocks in AMS

\subsubsection{BDA to Predict the Economic Shocks}

Financial crises constitute diverse economic and social costs therefore, governments and policymakers are largely concerned about the timely detection of early warning signs [44,45]. Predicting crises caused by an outbreak will facilitate policymakers in activating countercyclical macroprudential policies to lessen the plausibility of financial crises during the evaluation of risks [46]. Selecting early warning signs as predictors and human-based techniques are controversial, as humans incline to rely on the number of predictors instead of the number of observations. Previously, federal reserves and monetary policies were blamed for the severity of financial crises [47]. However, economists, policymakers, and businesses require real-time data to form their forecasts. Therefore, using digital technology such as BDA to predict the onset of 
crises is an effective method, especially, in the face of the current global situation caused by Covid-19, which also incidentally accelerated digitalisation [48].

New sources of economic information such as those from private data collection done by search engines, social media platforms, and internet companies are a potential source of real-time data known as BD. The ability of BDA to predict financial crises came into press spotlight when the U.S Federal Reserve accidentally published economic forecasts for the next five years on their website, predicting that the world will not face a recession before 2020 [49]. The forecast was made by monthly estimation of quarterly GDP data which was later revised due to a decline in GDP growth.

Our proposed model predicts the onset of economic shocks in AMS through BDA of economic indicators of GDP growth, trade performance, businesses yield, MSMEs performance, and financial markets performance using a machine learning technique. Studies in the past deployed similar economic indicators; domestic production curve [50], credit and financial stability [51], and domestic credit growth [52] to predict the sudden appearance of economic crises. Machine learning techniques used to predict economic shocks were recently used by several authors. "Ref. [53] predicted banking and currency related crises in EU countries by estimating quarterly data between 1970 and 2012." Ref. [54] employed machine learning techniques to predict banking and currency related crises in 36 advance economies. Ref. [55] concluded that neural networks are a better source to predict economic shocks compared to traditional techniques. Ref. [56] employed BDA to forecast economic shocks by using directed algorithmic text analysis and concluded that households and non-financial corporate debts are strong indicators of recession, whereas, the public sector debts and GDP ratios are not strong indicators. Similarly, [57] employed a machine learning approach to predict the onset of economic crises in 17 advance economies and suggested that domestic and global credit growth and yields are significant predictors. AMS economies are devastated (discussed in section 2) due to the emergence of Covid-19 and navigating BDA of the economic indicators proposed in this study, could be an effective method to curb the economic shocks by early prediction.

\subsubsection{BDA to Track Covid-19 Associated Economic Shocks}

$\mathrm{BD}$ is a potential resource to track economic shocks spurred by Covid-19, which can help in developing economic policies and decisions. Traditionally, policymakers used to make decisions based on the employment and business activities data, retrieved from domestic surveys of households and businesses. Although BDA has a great value in understanding the economy, there are certain limitations present that are now noticeable in the face of the fast-spreading pandemic [58].

Recent studies and reports have used different methods of BDA to analyse and recommend policymaking tools to track the economic shocks caused by Covid-19. For instance, [59] used BD related to 2.1 billion transactions from credit and debit cards to measure consumption patterns in Spain and found that the consumption patterns closely matched with official household budget surveys. A Harvard based institute of social scientists and policy analysts harnessed BD for policy solutions and designed 'Opportunity Insights Economic Tracker' to assist policymakers in U.S to analyse the effects of lockdowns on regional economies. This tool provides a real-time analysis of the data to the policymakers, especially, those related to consumer spending patterns and job postings [60]. In the context of Covid-19, a U.S based Centre for Strategic and International Studies is an effective platform to track global economic progress.

Every day, billions of searches are plugged into Google, Bing, and other search engines, generating a huge amount of data related to consumer spending. Policymakers can track the spending patterns related to consumer needs and wants by analysing BDA of Google searches on cars, road traffic, energy usage and bookings including those for restaurants and hotel reservations made via sites like booking.com and Airbnb. Data from these sources act as BD and a careful analysis of this data can help policymakers to track the economic situation and progress of the different sectors in the country [61]. 
$\mathrm{BD}$ has evolved as an essential paradigm to create value and implant growth for industries, businesses and science through large data volume [62]. AMS has established a virtual centre (ABVC) to visualise the $\mathrm{BD}$, however, policymakers have not focused on the economic situation in their reports. Our model suggests the urgency of developing and updating economic trackers at the domestic level across all AMS to curb Covid-19 shocks. As AMS slowly enter into the fifth stage of lockdowns, it necessitates the importance of reopening economies and starting the economic recovery process. The only way forward for AMS is to first focus on developing a platform containing BDA to track real-time economic situations, as BDA of relevant indicators truly measures the changes in key sectors of the economy [63].

\subsubsection{BDA to Initiate an Economic Recovery Process}

Currently, no officially approved solution exists to address and suggest the initiation of an economic recovery process. Policymakers and governments are using a plethora of policies, such as fiscal financial support for various economic sectors, in collaboration with IMF, The World Bank, and the Asian Development Bank (ADB), to ease the socio-economic situation across the world [24]. This was mainly due to the lack of infrastructure and preparedness to tackle the Covid-19 crisis. According to WHO's universal health coverage index of services, AMS scored a median index of 61 out of 100, suggesting a dire need for progress. This is particularly true in the context of the economic situation in the countries where more than half of the AMS regions including Myanmar, Cambodia, Indonesia, Laos PDR, and the Philippines are vulnerable to economic shocks due to the informal nature of their economies [24]. Additionally, governments and policymakers are waging a war against economies instead of Covid19 that has worsened the economic shocks mainly due to wrong interventions [64].

BDA is proposed as a pragmatic solution to address GDP growth output, trade, tourism, businesses, and production issues in AMS. However, extraction of real-time data and harnessing the actual value of BDA is a major concern for policymakers. [65] has proposed a 5Vs model (volume, velocity, variety, value, and veracity) of $\mathrm{BD}$, with an additional dimension of 'veracity' which determines a proper data governance and privacy concerns. This new paradigm of the $\mathrm{BD}$ model can help policymakers to develop an infrastructure to transform the landscape of socio-economic policies. The current economic situation resulted from Covid-19's demand of infrastructure for BD systems, based on an analysis of the economic situation in the region. In the past, studies have proposed different BDA architectures based on the nature of the problem [66,67]. The economic situation in AMS is highly unpredictable due to the uncertainties affiliated with Covid-19 therefore, tackling these uncertainties require a holistic BDA architecture to harvest the low hanging fruits of BDA.

We propose a holistic architecture to leverage on BDA as a policymaking tool to initiate the economic recovery process. Firstly, policymakers need to focus on how to turn unstructured heterogeneous data into knowledge. We propose a three-layer BDA architecture for AMS policymakers to consider. These are known as data analysis layer, governance layer, and persistence layer [68]. The data analysis layer entails the processes required to generate knowledge from the reports, forecasts, and to the different data sources

to which policymakers have access to. This layer has an additional six modules ranging from data reception to results publishing.

The current situation requires AMS to receive data on GDP growth, trade, production, business performance, tourism, supply and demand, and consumer spending patterns from reliable sources. After receiving data, pre-processing is required for validation, authenticity, and extraction of key features of the data. In the context of Covid-19, these key features are data related to the marginalised and vulnerable sectors in the economy which require fiscal financial support. Through a data integration module, policymakers need to ensure the homogenous access of data to the governments. The data preparation module refers to preparing data for analysis according to the format expected and the features of the data to be analysed prior. The analysis module represents the methods used to develop the basis of knowledge 
and future forecasts. Publishing results in the form of reports, tables, graphs, and charts would help provide a policymaking tool for governments to direct a particular policy for the welfare of Covid-19 affected industry sectors and societies. The governance layer represents the application of policies and regulations by the government to the whole data life cycle. Lastly, the persistence layer supports the other two layers by managing issues related to storage needs. Our three-layer BDA architecture is simple yet an effective policymaking tool that AMS governments and policymakers can adopt to initiate an economic recovery process and to address economic shock issues in the face of Covid-19. Data standardisation, availability, and scalability are the major challenges in the commercial application of BD [69]. This large-scale data

sharing is manageable through secure Cache Decision System that will ensure efficiency and effectiveness during this process [70]

\subsubsection{BDA to Design an Economic Recovery Plan}

After proposing the initiation of the recovery plan, we embark on how to implement a recovery plan by leveraging on BDA. IoT have been widely used in to create smart decision support system to achieve optimal performance through effective managing, compressing and mining of big data [71]. AMS governments have designed various fiscal financial support packages to cushion the economies and survive the Covid-19 crisis. For instance, among the AMS, Singapore introduced the largest financial support package of S\$90.4 billion for the businesses and workers affected [72]. However, the effectiveness and success of these stimulus packages rely on the proper navigation of data tools. Policymakers need to ensure that all of its macrofinancial and structural tools are effectively mobilised so that the dreadful acceleration of Covid-19 economic shocks is curtailed. AMS economies are entering into the fifth stage of lockdowns while, the rest of the world continues to also fight Covid-19. AMS economies substantially rely on revenues generated from other countries through trade, tourism, export, and investments. Covid-19 has largely affected the economies of AMS strategic partners such as China, U.S and EU. This has escalated supply and demand disproportion ultimately resulting in low demand of domestic goods in international markets, a decline in production capacity of firms, decline in trade and tourism, disruption of financial markets, and eventually lower GDP growth.

Policymakers can employ BDA to lower demand and supply imbalances that will help to reduce the risks of production issues in firms. In addition, the machine learning methods are effective tools to analyse consumer preferences and spending patterns therefore, policymakers need to focus on receiving and gathering relevant information from their data sources. Governments may use BDA, such as Lexian based features, to remove bureaucratic and taxation hurdles and adjust the leaning supply chains for the smooth flow of goods and services. This technique is also applicable to ensure the welfare of marginalised and vulnerable communities in AMS, which are most affected due to Covid-19. Ref. [73] proposed to leverage on BDA to characterise populations which require an immediate government attention during a natural disaster. This study proposes to advance this similar approach and suggests policymakers to use other BDA methods. Examples include receiver operating characteristics to evaluate the performance of Covid-19 related economic shocks and develop strategies based on the resilience level of different industry sectors in the economy, which will help in identifying the industries in need of immediate governmental bailouts.

\section{Conclusion and Policy Implications}

The governments and policymakers in AMS are actively identifying resources to start the economic recovery process, while most countries enter into the fifth stage of lockdowns due to the pandemic. The unique characteristics of data science models, particularly BDA can help in predicting and tracking economic shocks which resulted from Covid-19 and act as a medium to pave the way in designing an economic recovery process. Explicitly, this study found that BDA techniques such as machine learning, 
acquisition of real-time data from social networking sites, three layered data architecture and BDA based Lexian and receiver-based characteristics can help to predict, detect, track economic shocks, and suggest economic recovery plans. These approaches also provide guidelines for governments and policymakers to implement the recovery plans. While BDA is authenticated as a pragmatic solution to start the economic recovery process, there are certain implications to be considered by the policymakers.

\subsection{Overcome Data Limitations}

Generally, data science systems learn and improve over time due to large data volume. The ideal scenario for the proposed model in this study relies on higher data fidelity and volume. However, to implement the above plans, extensive datasets are not available, for instance, data on how Covid-19 has affected consumer spending patterns, in order to base our projections on the socioeconomic impact of Covid-19 on vulnerable economic sectors of the community. These smaller datasets are unsuitable to deploy machine learning models, due to the distributed nature of the different data sources. This refers to the exigency of improved and automated approaches through common standards and international collaborations to mung and wrangle data which may help in obtaining quick, consistent, and functional outcomes. Besides data availability, there are underlining issues within the data itself especially, ones related to quality and accuracy. For instance, data on firms' production, business performance, and consumer spending patterns amid Covid-19 may be obsolete by the time it is obtained, curated, and annotated to draw a conclusion. This consequence may lower the effectiveness of a policymaking tool developed based on the analysis of such data. Policymakers may thus need to employ specialised transfer learning models with regional characteristics to devise analytical approaches that can be effective within the data limitations.

\subsection{Prioritise Accuracy over Urgency}

The current situation clearly demands the urgency of identifying methods to initiate economic recovery plans and mitigate Covid-19 related economic shocks. The methods and techniques of BDA proposed in this study are successfully applied by different industries under different settings in the past. However, there is a high risk of bias due to exclusion of data of other economic indicators which may severely impact the policies designed for economic recovery in the fast-moving nature of the current crises. Therefore, policymakers need to focus on the inclusion of data from all economic indicators from all of its available sources. Conventionally, outcomes from researches often help governments in strategic decision making and policy development. For example, based on the Lexian technique, a government may introduce a stimulus package for a specific population of society or sector of industry. Therefore, policymakers need to ensure an equilibrium between exigency and evidence-based results to propose a policy.

\subsection{Address Ethical, Security and Privacy Issues}

The proposed model and techniques imply acquisition, sharing, and processing of sensitive data which raise issues of ethics and protection of users' privacy and security. However, the situation imposed by Covid19 has escalated a dilemma among policymakers, whether to choose a trade-off between creating solutions or being ethical. Policymakers may use simple techniques to move forward, for instance, ensuring the transparency (user is informed) during data collection, keeping users' anonymity, and improving the data governance framework.

\subsection{Focus on Multidisciplinary Collaboration}

Policymakers need to focus on multidisciplinary collaboration at regional levels to understand the longterm economic impacts of Covid-19. This will allow collaborating with experts from multidisciplinary fields to push for an internationally acceptable economic recovery plan. The implication of black-box models may 
provide solutions with superficial protection, which is impossible without engaging economists and experts' interpretations.

\subsection{Switch to Digital Trade}

The future remains highly uncertain on the point of the pandemic subsiding therefore, AMS need to start leveraging on digital trade to resume economic frontiers and thus mitigate existing and future production loss. Policymakers need to ensure the provision of secure digital platforms that will create an opportunity and train the public to harness social networking sites (SNS) for businesses, which alternatively can help policymakers in generating data for future policy decisions. The governments need to address the digital trade divide at regional and domestic levels on an urgent basis to improve cybersecurity for a better digital trade within their societies.

Funding Statement: This work was partially supported by in part by Universiti Islam Sultan Sharif Ali, Brunei Darussalam under grant (PPP/ULRGC/S2019-2020/6) funded by the Ministry of Education Brunei Darussalam.

Conflicts of Interest: The authors declare that they have no conflicts of interest to report regarding the present study.

\section{References}

[1] World Health Organization (WHO), "Rolling updates on coronavirus disease (Covid-19)," 2020. [Online]. Available: https:/www.who.int/emergencies/diseases/novel-coronavirus-2019/events-as-they-happen.

[2] World Health Organization (WHO), "WHO Coronavirus disease (COVID-19) dashboard-situation by WHO region," 2020. [Online]. Available: https://covid19.who.int/.

[3] OECD, "Enterprise policy responses to Covid-19 in ASEAN," 2020. [Online]. Available: https://asean.org/ storage/2012/05/Policy-Insight-Enterprise-Policy-Responses-to-COVID-19-in-ASEAN-June-2020.pdf.

[4] The World Bank, "The Global economic outlook during the Covid-19 pandemic: A changed world," 2020. [Online]. Available: https://www.worldbank.org/en/news/feature/2020/06/08/the-global-economic-outlookduring-the-covid-19-pandemic-a-changed-world.

[5] The Economist, "The 90\% economy that lockdowns will leave behind," 2020. [Online]. Available: https://www. economist.com/briefing/2020/04/30/the-90-economy-that-lockdowns-will-leave-behind.

[6] Q. He, J. Liu, S. Wang and J. Yu, "The impact of COVID-19 on stock markets," Economic and Political Studies, vol. 8, no. 3, pp. 275-288, 2020.

[7] N. M. Ferguson, D. Laydon, G. Nedjati-Gelani, N. ImaI, K. Ainseli et al., "Impact of non-pharmaceutical interventions (NPIs) to reduce Covid-19 mortality and healthcare demand," 2020. [Online]. Available: https:// www.imperial.ac.uk/media/imperial-college/medicine/sph/ide/gida-fellowships/Imperial-College-COVID19NPI-modelling-16-03-2020.pdf.

[8] O. Jorda, S. R. Singh and A. M. Taylor, "Long run economic consequences of pandemics," Federal Reserve Bank of San Francisco, Working Paper, 2020-09, 2020. [Online]. Available: https://www.frbsf.org/economic-research/ files/wp2020-09.pdf.

[9] O. Jorda, S. R. Singh and A. M. Taylor, "Long run economic consequences of pandemics," Federal Reserve Bank of San Francisco, Working Paper, 2020-09, 2020. [Online]. Available: https://www.frbsf.org/economic-research/ files/wp2020-09.pdf.

[10] Oxford Economics, "The economic impact of Covid-19 on Asia Pacific," 2020. [Online]. Available: https://www. oxfordeconomics.com/recent-releases/The-Economic-Impact-of-COVID-19-on-Asia-Pacific.

[11] Bloomberg, "S\&P 500 erases June losses after record home sales: Market wrap," 2020. [Online]. Available: https://www.bloomberg.com/news/articles/2020-06-28/asian-stocks-to-decline-yen-edges-higher-markets-wrap.

[12] ASEC, "ASEAN policy brief: Economic impact of Covid-19 outbreak on ASEAN. Jakarta: ASEAN secretariat," 2020. [Online]. Available: https://asean.org/storage/2020/04/ASEAN-Policy-BriefApril-2020_FINAL.pdf. 
[13] World Trade Organization (WTO), "Trade set to plunge as Covid-19 pandemic upends global economy," 2020. [Online]. Available: https://www.wto.org/english/news_e/pres20_e/pr855_e.pdf.

[14] Association of Southeast Asian Nations (ASEAN), “About ASEAN,” 2020. [Online]. Available: https://asean.org/ asean/aboutasean/overview/.

[15] C. S. Currie, J. W. Fowler, K. Kotiadis, T. Monks, B. S. Onggo et al., "How simulation modelling can help reduce the impact of Covid-19," Journal of Simulation, vol. 14, no. 2, pp. 83-97, 2020.

[16] A. S. S. Rao and J. A. Vazquez, "Identification of COVID-19 can be quicker through artificial intelligence framework using a mobile phone-based survey in the populations when cities/towns are under quarantine," Infection Control \& Hospital Epidemiology, vol. 41, no. 7, pp. 826-830, 2020.

[17] E. Maddah and B. Beigzadeh, "Use of a smartphone thermometer to monitor thermal conductivity changes in diabetic foot ulcers: A pilot study," Journal of Wound Care, vol. 29, no. 1, pp. 61-66, 2020.

[18] L. Ferretti, C. Wymant, M. Kendall, L. Zhao, A. Nurtay et al., "Quantifying SARS-CoV-2 transmission suggests epidemic control with digital contact tracing," Science, vol. 368, no. 6491, pp. 1-8, 2020.

[19] L. Li, Q. Zhang, X. Wang, J. Zhang, T. Wang et al., "Characterizing the propagation of situational information in social media during Covid-19 epidemic: A case study on Weibo," IEEE Transactions on Computational Social Systems, vol. 7, no. 2, pp. 556-562, 2020.

[20] J. Jumper, K. Tunyasuvunakool, P. Kohli, D. Hassabis and The Alpha Fold Team, "Computational predictions of protein structures associated with Covid-19," 2020. [Online]. Available: https://deepmind.com/research/opensource/comp.

[21] C. Stergiou, K. E. Psannis, B. B. Gupta and Y. Ishibashi, "Security, privacy \& efficiency of sustainable Cloud computing for big data \& IoT, Sustainable Computing," Informatics and Systems, vol. 19, pp. 174-184, 2018.

[22] N. Henke, A. Puri and T. Saleh, "Accelerating analytics to navigate Covid-19 and the next normal," McKinsey \& Company, 2020. [Online]. Available: https://www.mckinsey.com/business-functions/mckinsey-analytics/ourinsights/accelerating-analytics-to-navigate-covid-19-and-the-next-normal.

[23] S. Kidd, D. Athias and A. Tran, "Addressing the Covid-19 economic crisis in Asia through social protection," United Nations Development Programme report on Asia \& Pacific, 2020. [Online]. Available: https://www. developmentpathways.co.uk/wp-content/uploads/2020/05/Social-Protection-and-Covid-19-in-Asia.pdf.

[24] United Nations Economic and Social Commission for Asia and the Pacific (UNESACP), "Policy brief: The impact of Covid-19 on South-East Asia," 2020. [Online]. Available: https:/www.unescap.org/sites/default/ d8files/2020-07/SG-Policy-brief-COVID-19-and-South-East-Asia-30-July-2020.pdf.

[25] European Commission, "Business and consumer surveys," 2020. [Online]. Available: https://ec.europa.eu/info/ business-economy-euro/indicators-statistics/economic-databases/business-and-consumer-surveys_en.

[26] The World Bank, "Global economic prospects: Heightened tensions, subdued investment," 2020. [Online]. Available: http://pubdocs.worldbank.org/en/308981560187921635/211398-Ch01.pdf.

[27] P. Bretschneider, S. Cirilli, T. Jones, S. Lynch and N. Wilson, "Document review as a qualitative research data collection method for teacher research," SAGE Research Methods Cases, 2017.

[28] G. A. Bowen, "Document analysis as a qualitative research method," Qualitative Research Journal, vol. 9, no. 2, pp. 27-40, 2009.

[29] W. Potter, "A history of influenza," Journal of Applied Microbiology, vol. 91, no. 4, pp. 572-579, 2001.

[30] E. D. Kilbourne, "Influenza pandemics of the 20th century," Emerging Infectious Diseases, vol. 12, no. 1, pp. 9-14, 2006.

[31] A. Haleem, M. Javaid, I. H. Khan and R. Vaishya, "Significant applications of big data in COVID-19 pandemic," Indian Journal of Orthopaedics, vol. 54, no. 4, pp. 526-528, 2020.

[32] C. J. Wang, C. Y. Ng and R. H. Brook, "Response to Covid-19 in Taiwan: big data analytics, new technology, and proactive testing," JAMA, vol. 323, no. 14, pp. 1341-1342, 2020.

[33] Y. Bai, L. Yao, T. Wei, F. Tian, D. Y. Jin et al., "Presumed asymptomatic carrier transmission of COVID-19," $J A M A$, vol. 323, no. 14, pp. 1406-1407, 2020. 
[34] M. Lenca and E. Vayena, "On the responsible use of digital data to tackle the COVID-19 pandemic," Nature Medicine, vol. 26, no. 4, pp. 463-464, 2020.

[35] S. V. Scarpino and G. Petri, "On the predictability of infectious disease outbreaks," Nature Communications, vol. 10, pp. 898, 2019.

[36] D. S. W. Ting, L. Carin, V. Dzau and T. Y. Wong, "Digital technology and COVID-19," Nature Medicine, vol. 26, no. 4, pp. 459-461, 2020.

[37] C. M. Chen, H. W. Jyan, S. C. Chien, H. H. Jen, C. Y. Hsu et al., "Containing Covid-19 among 627,386 persons in contact with the Diamond Princess cruise ship passengers who disembarked in Taiwan: Big data analytics," Journal of Madicle Internet Research, vol. 22, no. 5, pp. 19540, 2020.

[38] T. T. Nguyen, "Artificial intelligence in the battle against coronavirus (Covid-19): A survey and future research directions," TechRxiv. Preprint, 2020.

[39] O. Gozes, M. Frid-Adar, H. Greenspan, P. D. Browning, H. Zhang et al., "Rapid AI development cycle for the Coronavirus (Covid-19) pandemic: Initial results for automated detection \& patient monitoring using deep learning CT image analysis," 2020.

[40] J. T. Wu, K. Leung and G. M. Leung, "Nowcasting and forecasting the potential domestic and international spread of the 2019-nCoV outbreak originating in Wuhan, China: A modelling study," The Lancet, vol. 395, no. 10225, pp. 689-697, 2020.

[41] M. Gilbert, G. Pullano, F. Pinotti, E. Valdano, C. Poletto et al., "Preparedness and vulnerability of African countries against importations of COVID-19: A modelling study," The Lancet, vol. 395, no. 10227, pp. 871$877,2020$.

[42] A. Searight, "The economic toll of Covid-19 on Southeast Asia: recession looms as growth prospects dim," Centre for Strategic and International Studies, 2020. [Online]. Available: https://www.csis.org/analysis/economic-tollcovid-19-southeast-asia-recession-looms-growth-prospects-dim.

[43] United Nations Economic and Social Commission for Asia and the Pacific (UNESACP), "Inequality of opportunity in Asia and the Pacific," Social Development Policy Papers, 2018. [Online]. Available: https:// www.unescap.org/sites/default/files/Education\%20report\%2018042018.pdf.

[44] L. Luc and F. Valencia, "Systemic banking crises revisited," IMF Working Papers 18/206, 2018. [Online]. Available: https:/www.imf.org/en/Publications/WP/Issues/2018/09/14/Systemic-Banking-Crises-Revisited-46232.

[45] A. David, A. Haldane, M. Hinterschweiger and S. Kapadia, "Rethinking financial stability," Bank of England working papers 712, Bank of England, 2018. [Online]. Available: https://www.bankofengland.co.uk/-/media/boe/files/workingpaper/2018/rethinking-financial-stability.pdf?la=en\&hash=6A14C6F12C1DEFFDD57BD5C3255493BFE5F02060.

[46] O. Akinci and J. Olmstead-Rumsey, "How effective are macroprudential policies? An empirical investigation," Journal of Financial Intermediation, vol. 33, pp. 33-57, 2018.

[47] M. Friedman and A. Schwartz, "A monetary history of the United States," NJ, USA: Princeton University Press, pp. 888, 1963.

[48] KPMG, "How Covid-19 is accelerating digitalisation," 2020. [Online]. Available: https://home.kpmg/in/en/blogs/ home/posts/2020/07/how-covid-19-accelerating-digitalisation-banking-payments-industry.html.

[49] World Economic Forum, "What big data could do for economic forecasts," 2015. [Online]. Available: https:// www.weforum.org/agenda/2015/08/what-big-data-could-do-for-economic-forecasts/.

[50] G. D. Rudebusch and J. C. Williams, "Forecasting recessions: The puzzle of the enduring power of the yield curve," Journal of Business \& Economic Statistics, vol. 27, no. 4, pp. 492-503, 2009.

[51] N. Coimbra and H. Rey, "Financial cycles with heterogeneous intermediaries," Working Paper No. 23245, MA, USA: National Bureau of Economic Research, Inc, 2017.

[52] J. Giese, H. Andersen, O. Bush, C. Castro, M. Farag et al., "The credit-to-GDP gap and complementarity indicators for macroprudential policy: Evidence from the UK," International Journal of Finance \& Economics, vol. 19, no. 1, pp. 25-47, 2014.

[53] L. Alessi and C. Detken, "Identifying excessive credit growth and leverage," Journal of Financial Stability, vol. 35 , pp. 215-225, 2018. 
[54] M. Joy, M. Rusnák, K. Šmídková and B. Vašíček, "Banking and currency crises: Differential diagnostics for developed countries," International Journal of Finance \& Economics, vol. 22, no. 1, pp. 44-67, 2017.

[55] E. Tolo, "Predicting systemic financial crises with recurrent neural networks," Journal of Financial Stability, vol. 49, 2020.

[56] R. Nyman and P. Ormerod, "Understanding the great recession using machine learning algorithms," 2020. [Online]. Available: https://arxiv.org/ftp/arxiv/papers/2001/2001.02115.pdf.

[57] K. Bluwstein, M. Buckmann, A. Joseph, M. Kang, S. Kapadia et al., "Credit growth, the yield curve and financial crisis prediction: Evidence from a machine learning approach," Working Papers, No. 848, London, UK: Bank of England, 2020.

[58] R. Chetty, J. N. Friedman, N. Hendren and M. Stepner, "Real-time economics: A new platform to track the impacts of Covid-19 on people, businesses, and communities using private sector data," Opportunity Insights Team, 2020. [Online]. Available: https://opportunityinsights.org/wp-content/uploads/2020/06/Short_Covid_Paper.pdf.

[59] V. M. Carvalho, S. Hansen, A. Ortiz, G. J. Ramon, T. Rodrigo et al., "Tracking the Covid-19 crisis with highresolution transaction data," CEPR Discussion Paper No. DP14642, 2020. [Online]. Available: https://ssrn. com/abstract $=3594273$.

[60] J. Siliezar, "Real-time data to address real-time problems," The Harvard Gazette, 2020. [Online]. Available: https://news.harvard.edu/gazette/story/2020/05/a-tool-to-provide-policymakers-with-real-time-data/.

[61] R. Partington, "Recession in real time: how big data can track the Covid slump," The Guardian, 2020. [Online]. Available: https://www.theguardian.com/business/2020/aug/08/recession-in-real-time-big-data-covid-slumpeconomy-unconventional-indicators.

[62] V. Grover, R. H. Chiang, T. P. Liang and D, "Zhang Creating strategic business value from big data analytics: A research framework," Journal of Management Information Systems, vol. 35, no. 2, pp. 388-423, 2018.

[63] Financial Times, "Pandemic crisis: Global economic recovery tracker," 2020. [Online]. Available: https://www.ft. com/content/272354f2-f970-4ae4-a8ae-848c4baf8f4a.

[64] G. D. Snooks, "Will the world ever recover from the great lockdown? Counting the costs of waging war on the economy," Institute of Global Dynamic Systems Canberra, Working Papers \#21, 2020.

[65] G. Bello-Orgaz, J. J. Jung and D. Camacho, "Social big data: Recent achievements and new challenges," Information Fusion, vol. 28, pp. 45-59, 2016.

[66] Y. Zhang, S. Ren, Y. Liu and S. Si, "A big data analytics architecture for cleaner manufacturing and maintenance processes of complex products," Journal of Cleaner Production, vol. 142, no. 2, pp. 626-641, 2017.

[67] Y. Wang, L. Kung and T. A. Byrd, "Big data analytics: Understanding its capabilities and potential benefits for healthcare organizations," Technological Forecasting and Social Change, vol. 126, pp. 1-11, 2016.

[68] D. Blazquez and J. Domenech, "Big data sources and methods for social and economic analyses," Technological Forecasting and Social Change, vol. 130, pp. 99-113, 2018.

[69] R. Hassan, F. Qamar, M. K. Hasan, A. H. mohd-Aman and M. S. Ahmed, "Internet of things and its applications: A comprehensive survey," Symmetry, vol. 12, no. 10, pp. 1674, 2020.

[70] C. L. Stergiou, K. E. Psannis and B. B. Gupta, "IoT-based Big Data secure management in the Fog over a 6G wireless network," in IEEE Internet of Things Journal, 2020.

[71] K. Hossain, M. Rahman and S. Roy, "IoT data compression and optimization techniques in Cloud storage: Current prospects and future directions," International Journal of Cloud Applications and Computing, vol. 9, no. 2, pp. 43-59, 2019.

[72] KPMG, "Government and institution measures in response to Covid-19-Singapore," 2020. [Online]. Available: https:/home.kpmg/xx/en/home/insights/2020/04/Singapore-government-and-institution-measures-in-responseto-covid.html.

[73] J. R. Ragini, P. M. R. Anand and V. Bhaskar, "Big data analytics for disaster response and recovery through sentiment analysis," International Journal of Information Management, vol. 42, pp. 13-24, 2018. 